\title{
MÉTODO ALTERNATIVO PARA SUBMETER SEMENTES DE AMENDOIM À SOLUÇÃO DE TETRAZÓLIO ${ }^{1}$
}

\author{
NELSON MOREIRA DE CARVALHO², JOSUÉ BISPO DA SILVA ${ }^{3}$, CÉSAR MARTORELLI DA SILVEIRA ${ }^{4}$, \\ RENATA ALVES HORVAT ${ }^{5}$
}

\begin{abstract}
RESUMO - A técnica para a determinação da viabilidade de sementes de amendoim por meio do tetrazólio (TZ) é, atualmente, aquela pela qual as sementes, após embebição em água, têm o tegumento removido. A seguir as sementes são, em grupo, imersas na solução de TZ. Essa técnica dificulta o contato entre os tecidos das faces internas dos cotilédones e a solução de $\mathrm{TZ}$ em virtude de que o período prévio de embebição em água não é suficiente para que os cotilédones das sementes de amendoim se separem. Assim, o acesso da solução de TZ aos tecidos das faces internas dos cotilédones e ao próprio eixo embrionário, que fica entre as duas faces cotiledonares internas, é consideravelmente dificultado. Na suposição de que este procedimento levaria a resultados de testes de TZ que se correlacionam mal com o desempenho germinativo das sementes no campo, tentou-se uma nova técnica pela qual as sementes, após a embebição em água, além de terem o tegumento removido, são manualmente separadas em seus cotilédones, com o eixo embrionário ligado a um deles, e os cotilédones de uma determinada semente, agora separados, imersos na solução de TZ contida em uma célula individual de uma bandeja de PVC. A hipótese aqui formulada mostrouse correta : a técnica alternativa de submissão das sementes de amendoim à solução de tetrazólio permitiu a obtenção de resultados que, comparados com os da técnica convencional, refletiram de modo mais preciso o desempenho germinativo das sementes no campo.
\end{abstract}

Termos para indexação: Arachis hypogaea, determinação da viabilidade de sementes, emergência de plântulas

\section{AN ALTERNATIVE METHOD FOR SUBMITTING PEANUT SEEDS TO TETRAZOLIUM SOLUTION}

\begin{abstract}
To determine the viability of peanut seeds by means of the tetrazolium (TZ) test, the methodology in use nowadays is that by which the seeds, after imbibition in water, have their tegument removed and are then immersed in bulk in the TZ solution. This technique hinders the contact between the tissues of the internal surfaces of the seed cotyledons and the TZ solution because the previous period of water imbibition is not long enough to separate the cotyledons. Thus, the access of the TZ solution to the inner surfaces of the cotyledons and to the embryonic axis between them is very difficult or even impossible. Based on the assumption that this procedure tends to yield results which do not correlate well with seedling emergence in the field, a new technique was attempted by which the seeds, after imbibition, in addition to having their tegument removed, were manually separated in their cotyledons, with the embryonic axis remaining attached to one of them, and the two
\end{abstract}

${ }^{1}$ Submetido em 04/03/2008. Aceito para publicação em 22/07/2008.

${ }^{2}$ Prof. Dr. Departamento de Produção Vegetal. FCAV/UNESP, 14884-900

- Jaboticabal, SP, nmc@fcav.unesp.br

${ }^{3}$ Prof. Dr. Departamento de Ciências Agrárias. UFAC， 69915 - 900 - Rio
Branco, AC

${ }^{4}$ UNESP, campus de Jaboticabal, Doutorando em Produção e Tecnologia de Sementes.

${ }^{5}$ UNESP, campus de Jaboticabal, Graduanda em Agronomia. 
cotyledons of the same seed were then immersed in the TZ solution in an individual cell of a PVC tray. The assumption was found to be correct : the alternative technique, probably because it resulted in more clearly defined images of the tissues located inside the cotyledons internal surfaces, allowed, in comparison with the results of the conventional technique, more precise predictions of the seeds germination performance in the field.

Index terms : Arachis hypogaea, seed viability determination, seedling emergence

\section{INTRODUÇÃO}

A utilização de sementes com alto padrão de qualidade é fator de extrema importância para a obtenção da população adequada de plantas. Deve-se considerar que as sementes de alta qualidade influem diretamente no sucesso da lavoura e contribuem significativamente para que níveis de alta produtividade sejam alcançados para as espécies vegetais cultivadas. Somente quando essa condição for atendida é que se conseguirá a almejada máxima produtividade. Assim, o uso de testes que avaliem a viabilidade das sementes, constituise em um dos desafios para a pesquisa sobre qualidade de sementes, a fim de se evitar ou diminuir os prejuízos da utilização de sementes de baixo potencial germinativo.

Uma das metodologias mais empregadas para esse fim é o teste de germinação. A porcentagem de plântulas normais obtida nesse teste, como medida da qualidade do lote de sementes, é um pré-requisito importante na implantação das culturas, uma vez que determina o número de sementes a serem semeadas por metro de sulco com o objetivo de se obter a população desejada (Garcia et al., 1998.

O fator tempo, no entanto, é, sem dúvida, uma das grandes limitações do teste de germinação (Rego Barros e Marcos Filho, 1990) que, se longo, inviabiliza a tomada de decisões sobre os processos de beneficiamento e armazenamento dos lotes produzidos (Delouche, 1976) e, num programa de produção de sementes, é interessante que se avalie a qualidade antes da colheita, permitindo que lavouras, apresentando sementes com possíveis problemas de potencial fisiológico, sejam descartadas em tempo hábil para se evitar maiores prejuízos (Amaral, 1991).

Em amendoim, outra limitação do teste de germinação é que uma vasta gama de agentes patogênicos, principalmente fungos, pode estar interna e/ou externamente associada às sementes, interferindo negativamente nos resultados (Moraes, 1987).

Diversos procedimentos para avaliação da qualidade de sementes têm sido empregados e, entre eles, o teste do tetrazólio, que permite a obtenção de resultados com maior rapidez e precisão, equivalente à do teste de germinação, fornecendo, adicionalmente, informações sobre as possíveis causas de mau desempenho de um determinado lote, como danos mecânicos, deterioração por umidade, injúrias por insetos, danos de secagem, de estresse hídrico e de geadas (França Neto et al., 1998 ).

Em pesquisa com o objetivo de adaptar a metodologia do teste de tetrazólio para o amendoim, Bittencourt (1995) testou as temperaturas de 20,25 , 30 e $35^{\circ} \mathrm{C}$ e os períodos de 4,8 , 12,16 e 20 horas para o pré-condicionamento das sementes seguido da retirada, ou não, do tegumento das sementes. Para a coloração dos tecidos, duas repetições de sementes foram imersas em solução de tetrazólio nas concentrações de $0,05,0,075$ e $0,1 \%$ nas temperaturas de 35 e $40^{\circ} \mathrm{C}$. Na etapa seguinte, após a drenagem da solução e lavagem em água corrente, as sementes foram cortadas longitudinalmente, uma a uma, através da secção mediana do eixo embrionário e avaliadas quanto à intensidade de coloração. Uma das conclusões da autora é que a pré-embebição deve ser realizada a $20^{\circ} \mathrm{C}$ por 16 horas e que as sementes devem ser imersas inteiras, sem o tegumento, em solução de tetrazólio a $0,05 \%$ por três horas a $40{ }^{\circ} \mathrm{C}$. O período de imersão pode, segundo Bittencourt e Vieira (1999), ser reduzido para duas horas, desde que a concentração da solução seja de $0,75 \%$.

Este procedimento, ainda que representando um avanço na determinação da capacidade potencial de germinação de sementes de amendoim por meio do teste do tetrazólio, tem o inconveniente de que, ao colocar a semente de amendoim fechada na solução do tetrazólio, dificulta o contato entre a solução de tetrazólio e as faces internas dos cotilédones bem como com o próprio eixo embrionário, que se aloja entre os dois cotilédones. A remoção do tegumento antes da imersão na solução de tetrazólio não é suficiente para que os cotilédones se separem - eles continuam aderidos um ao outro. Fechados entre os dois cotilédones, as faces internas e o eixo embrionário, a solução de tetrazólio quase não entra em contato com eles, o que, praticamente, inviabiliza a obtenção de imagens definidas dessas estruturas.

Com base nessas considerações, o presente trabalho 
foi realizado com o objetivo de verificar se a separação manual da semente de amendoim em seus cotilédones para somente então submergi-la na solução de tetrazólio poderia dar resultados que refletissem melhor o desempenho das sementes no campo quando em comparação com o método preconizado por Bittencourt e Vieira (1999).

\section{MATERIAL E MÉTODOS}

No trabalho, realizado no Laboratório de Análise de Sementes da Universidade Estadual Paulista (UNESP), em seu campus de Jaboticabal, utilizaram-se sementes de amendoim provenientes de 4 lotes de cada uma das variedades IAC Tatu ST e IAC 886 (Runner). As sementes das duas variedades, pertencentes à safra colhida em 2006, foram obtidas junto à Cooperativa dos Plantadores de Cana da Zona de Guariba (COPLANA).

Para a metodologia do teste de tetrazólio à qual chamouse convencional, foram seguidos os procedimentos propostos por Bittencourt e Vieira (1999). Aproximadamente 100 sementes de cada lote de cada variedade foram colocadas para embeber água entre três folhas de papel toalha, umedecidas com quantidade de água equivalente a três vezes o peso do papel não hidratado. Assim, envolvidas em papel toalha, as sementes foram levadas para uma câmara tipo BOD, e lá deixadas por 16 horas, sob temperatura constante de $20{ }^{\circ} \mathrm{C}$. Em seguida à embebição em água, retirou-se, manualmente, o tegumento de cada semente. Duas repetições de 50 sementes de cada um dos lotes e variedades foram, em seguida, imersas em solução a 0,75\% de tetrazólio e aí mantidas por duas horas em temperatura de $40{ }^{\circ} \mathrm{C}$. Depois de expostas ao tetrazólio, as sementes foram seccionadas longitudinalmente para serem avaliadas com o auxílio de uma lupa de seis aumentos, sob luz fluorescente.

No método que se estabeleceu chamar de alternativo, o procedimento seguido foi o mesmo do convencional, exceto que, após a retirada do tegumento de cada semente, esta teve seus cotilédones manualmente separados os quais foram, então, imersos na solução de tetrazólio em células individuais de bandejas de PVC a fim de que, ao concluir o teste, no momento da avaliação dos resultados, se tivesse a certeza de se estar examinando os cotilédones da mesma semente.

Antes da instalação do teste de emergência de plântulas em campo, metade das sementes recebeu tratamento com thiram (3 gramas $\mathrm{kg}^{-1}$ de sementes). Quatro repetições de 50 sementes, tratadas e não tratadas, de cada lote e variedade, foram, então, semeadas em linhas com dois metros de comprimento, espaçadas de $0,5 \mathrm{~m}$, à profundidade de 2 a 3 $\mathrm{cm}$, distribuídas aleatoriamente dentro da área experimental.

$\mathrm{Na}$ avaliação estatística dos resultados, utilizou-se o delineamento em blocos ao acaso. Os dados de cada metodologia do teste de tetrazólio, convencional ou alternativa, foram comparados aos dados de emergência em campo, para sementes tratadas ou não. Como, pela análise de variância, foram observados valores não significativos de F para o efeito de lotes (Tabelas 1 e 2), a comparação entre os resultados dos testes de emergência em campo e os dos testes de tetrazólio feitos pela metodologia convencional e pela alternativa, tanto para sementes tratadas quanto não tratadas, foi feita considerando-se as médias dos quatro lotes das duas variedades. O procedimento estatístico considerou separadamente os resultados de cada uma das cultivares. As médias foram comparadas pelo teste de Tukey a 5\% de probabilidade, usando o programa SANEST (Zonta et al., 1985).

TABELA 1. Valores de F para a comparação entre o teste de emergência de plântulas em campo e o de tetrazólio convencional, para sementes tratadas (T) e não tratadas (NT) de duas variedades de amendoim.

\begin{tabular}{lcclcc}
\hline & \multicolumn{2}{c}{ IAC Tatu } & & \multicolumn{2}{c}{ IAC 886 } \\
\cline { 2 - 3 } \cline { 5 - 6 } & $\mathrm{T}$ & $\mathrm{NT}$ & & $\mathrm{T}$ & $\mathrm{NT}$ \\
\hline Lotes & $6,86 \mathrm{~ns}$ & $3,50 \mathrm{~ns}$ & & $0,85 \mathrm{~ns}$ & $0,14 \mathrm{~ns}$ \\
Testes & $17,11^{*}$ & $77,31^{* *}$ & & $2,31 \mathrm{~ns}$ & $117,67^{* *}$ \\
\hline
\end{tabular}

ns : não significativo

* : significativo a $5 \%$ de probabilidade

** : significativo a $1 \%$ de probabilidade

TABELA 2. Valores de F para a comparação entre o teste de emergência de plântulas em campo e o de tetrazólio alternativo para sementes tratadas (T) e não tratadas (NT) de duas variedades de amendoim

\begin{tabular}{lcclcc}
\hline & \multicolumn{2}{c}{ IAC Tatu } & & \multicolumn{2}{c}{ IAC 886 } \\
\cline { 2 - 3 } \cline { 5 - 6 } & $\mathrm{T}$ & $\mathrm{NT}$ & & $\mathrm{T}$ & $\mathrm{NT}$ \\
\hline Lotes & $0,49 \mathrm{~ns}$ & $0,65 \mathrm{~ns}$ & & $0,13 \mathrm{~ns}$ & $2,48 \mathrm{~ns}$ \\
Testes & $0,05 \mathrm{~ns}$ & $69,81^{* *}$ & & $1.64 \mathrm{~ns}$ & $349,34^{* *}$ \\
\hline
\end{tabular}

ns : não significativo

* : significativo a $5 \%$ de probabilidade

** : significativo a $1 \%$ de probabilidade 


\section{RESULTADOS E DISCUSSÃO}

Na variedade IAC Tatu ST, houve diferença entre o teste de tetrazólio convencional e o de emergência de plântulas em campo, tanto na comparação com sementes tratadas ( $\mathrm{P}$ $<0,05$ ), quanto não tratadas ( $\mathrm{P}<0,01$ ), conforme a Tabela 3. Para a variedade IAC 886, o potencial de germinação determinado pelo teste de tetrazólio convencional e de emergência de plântulas em campo mostrou-se semelhante para sementes tratadas, mas diferente $(\mathrm{P}<0,01)$ nas não tratadas (Tabela 4).

TABELA 3. Resultados de emergência no campo (EC) e do teste de tetrazólio convencional (TC) $\left({ }^{1}\right)$ de sementes de duas cultivares de amendoim, tratadas (T) e não tratadas (NT)

\begin{tabular}{lccccc}
\hline & \multicolumn{2}{c}{ IAC Tatu } & & \multicolumn{2}{c}{ IAC 886} \\
\cline { 2 - 3 } \cline { 5 - 6 } & T & NT & & T & NT \\
\hline EC & $79.3 \mathrm{a}$ & $41.5 \mathrm{~b}$ & & $66.0 \mathrm{a}$ & $29.5 \mathrm{~b}$ \\
$\mathrm{TC}$ & $68.0 \mathrm{~b}$ & $68.0 \mathrm{a}$ & & $60.5 \mathrm{a}$ & $60.5 \mathrm{a}$ \\
\hline DMS (Tukey) & 8.65 & 9.59 & & 11.51 & 9.09 \\
\hline $\mathrm{CV}(\%)$ & 5.22 & 7.78 & & 8.09 & 8.98 \\
\hline
\end{tabular}

$\left({ }^{1}\right)$ - cada um dos valores constantes da tabela representa a média dos 4 lotes de cada cultivar

Em cada coluna, valores seguidos da mesma letra não diferem entre si no nível de $5 \%$ de probabilidade, de acordo com o teste de Tukey.

TABELA 4. Resultados de emergência em campo (EC) e do teste de tetrazólio alternativo (TA) $\left({ }^{1}\right)$ de sementes de duas cultivares de amendoim tratadas e não tratadas

\begin{tabular}{|c|c|c|c|c|}
\hline & \multicolumn{2}{|c|}{ IAC Tatu } & \multicolumn{2}{|c|}{ IAC 886} \\
\hline & $\mathrm{T}$ & NT & $\mathrm{T}$ & NT \\
\hline & $-\ldots$ & - & $-\%-$ & - . - . \\
\hline $\mathrm{EC}$ & $79.3 \mathrm{a}$ & $41.5 b$ & $66.0 \mathrm{a}$ & $29.5 b$ \\
\hline TA & $78.0 \mathrm{a}$ & $78.0 \mathrm{a}$ & $73.0 \mathrm{a}$ & $73.0 \mathrm{a}$ \\
\hline DMS Tukey 5\%) & 18.20 & 13.90 & 17.38 & 7.41 \\
\hline $\mathrm{CV}(\%)$ & 10.29 & 10.34 & 11.11 & 6.42 \\
\hline
\end{tabular}

$\left({ }^{1}\right)$ - cada um dos valores constantes da tabela representa a média dos 4 lotes de cada cultivar.
Em cada coluna, valores seguidos da mesma letra não diferem entre si ao nível de 5\% de probabilidade, de acordo com o teste de Tukey.

Na comparação entre os testes de tetrazólio alternativo e de emergência de plântulas em campo da variedade IAC Tatu ST, não houve diferença entre os resultados desses dois testes nas sementes tratadas, mas nas não tratadas a diferença foi significativa ( $\mathrm{P}<0,01$ ), de acordo com a Tabela 2 , resultado este, semelhante ao encontrado na variedade IAC 886, no procedimento convencional em sementes tratadas ( Tabela 1). Na variedade IAC 886, à semelhança do que ocorreu com a variedade IAC Tatu, os resultados do método alternativo não diferiram dos determinados pelo teste de emergência de plântulas em campo para sementes tratadas ao passo que, nas sementes não tratadas, foi verificada diferença ( $\mathrm{P}<0,01$ ).

Nos dois métodos, e principalmente no alternativo, relação positiva com a emergência de plântulas em campo foi verificada apenas com sementes tratadas. A presença ativa de fungos, no momento em que a semente vai dar início ao processo de germinação, é reconhecidamente um dos mais sérios problemas para a obtenção do estande desejado na cultura do amendoim ( Moraes, 1987 ). Nesse sentido, Bittencourt ( 1995) verificou que o uso de sementes tratadas no teste de emergência de plântulas em campo permitiu alta correlação ( $r=0,95 ; \mathrm{P}<0,05$ ) com os resultados do teste de tetrazólio convencional.

A semelhança dos resultados obtidos pelo método convencional aproximou-se apenas da variedade IAC 886, enquanto os do método alternativo assemelhou-se para as duas variedades. Assim, além de permitir ganho de tempo, os resultados ressaltam a superioridade do método alternativo em relação ao convencional, na avaliação da viabilidade de sementes de amendoim.

\section{CONCLUSÕES}

O teste de tetrazólio alternativo é potencialmente viável para utilização na avaliação da viabilidade de sementes de amendoim.

\section{REFERÊNCIAS}

AMARAL, A. S. Testes rápidos para estimar a germinação de sementes. Lavoura Arrozeira, Porto Alegre, v. 44, n. 397, p. 10 - 14. 1991.

BITTENCOURT, S.R.M. Avaliação da qualidade fisiológica de sementes de amendoim através do teste de tetrazólio. 1995. 111f. Dissertação (Mestrado em Produção e 
Tecnologia de Sementes) - Faculdade de Ciências Agrárias e Veterinárias, Universidade Estadual Paulista, Jaboticabal, 1995

BITTENCOURT, S.R.M ; VIEIRA, R.D. Metodologia do teste de tetrazólio em amendoim. In : KRZYZANOWSKI, F.C.; VIEIRA, R.D.; FRANÇA NETO, J.B. Vigor de sementes : conceitos e testes. Londrina : ABRATES, 1999. cap. 8.2, p. 1-8.

DELOUCHE, J.C.; STILL, T.W.; RASPET, M.;LIENHARD, M. O teste de tetrazólio para a viabilidade de sementes. Brasilia : AGIPLAN, 1976, 103 p.

FRANÇA NETO, J.B.; KRZYZANOWSKI, F.C.; COSTA, N.P. O teste do tetrazólio em sementes de soja. Londrina : EMBRAPA - CANPSo, 1998. 72 p. (EMBRAPA-CANPSo. Documentos, 116 ).

GARCIA， R.; PEREIRA， O.G.; ALTUVE， S.M.; ALVARENGA, E.M. Efeitos do potencial hídrico na germinação de sementes de três gramíneas forrageiras tropicais. Revista Brasileira de Zootecnia, v. 27, n.1, p. 9 - 15, 1998.

MORAES, S.A. Testes de sanidade em sementes de amendoim. In : SOAVE, J.; WETZEL, M.M.V. (Eds.). Patologia de Sementes. 5. Ed. Campinas, Fundação Cargill, 1987. P. 347 - 357

REGO BARROS, A.S.; MARCOS FILHO, J. Testes para a avaliação rápida da viabilidade de sementes de soja. Pesquisa Agropecuária Brasileira, Brasilia, v. 25, n. 10, p. 1447 - 1459/ 1990.

ZONTA, E.F., MACHADO, A.A., SILVEIRA Jr., P. Sistema de análise estatística (SANEST) para microcomputador (versão 1.0). In : SIMPÓSIO DE ESTATÍSTICA APLICADA À EXPERIMENTAÇÃO AGRONÔMICA, 1985, Piracicaba, Anais... Piracicaba : ESALQ, p. 74 - 90, 1985. 